\title{
北京山区侧柏林坡面土壤水分时空动态及其影响因素
}

\author{
沈晗悦 ${ }^{1}$, 信忠保 ${ }^{1, *}$ ，王志杰 ${ }^{2}$ \\ 1 北京林业大学水土保持学院, 北京 100083 \\ 2 黄河上中游管理局, 陕西 710000
}

摘要:研究基于自然坡面土壤水分高密度观测方法,明确北京山区侧柏林自然坡面土壤水分动态变化特征、时间稳定性及其影 响因素,提升对北京山区坡面土壤水分时空动态及其影响因素的认识,为华北土石山区生态恢复对水文水资源影响评估提供依 据。研究以北京鹑峰国家森林公园人工侧柏林地坡面 $(40 \mathrm{~m} \times 50 \mathrm{~m})$ 为研究对象, 用 Diviner 2000 测量该自然坡面中 30 个测 点,于 2014 年 8 月至 2016 年 3 月对坡面观测砾石层以上的土壤含水量 (SWC) 进行了观测。结果表明: 观测期间土壤蓄水量 (SWS) 具有明显的季节变化特征且与降水量的变化趋势基本保持一致; 不同土层 SWC 均处于中等变异, SWC 较高时, SWC 的 变异性较低; 研究区的土壤水分在整个观测期间都具有较高的时间稳定性,位于上坡水平阶的 2 号测点最能代表研究区的平均 土壤水分; 随着离树距离的增加 SWS 逐渐增加,春、夏、秋季离树距离 $0.5 \mathrm{~m}$ 与 $1.5 \mathrm{~m}$ 处 SWS 差异显著 $(P<0.05)$; 水平阶 SWS 显著大于陡坎 $(P<0.05)$,夏、秋季下坡位土壤 SWS 显著低于上坡位 $(P<0.05)$, 水土保持工程措施对坡面 SWC 的分布格局有 重要的影响。

关键词: 北京山区; 土壤水分; 时间稳定性;季节动态;微地形

\section{Spatial and temporal dynamics of soil moisture and its influencing factors on the slope of Platycladus orientalis in Beijing mountain area}

\author{
SHEN Hanyue ${ }^{1}$, XIN Zhongbao ${ }^{1, *}$, WANG Zhijie ${ }^{2}$ \\ 1 College of Water and Soil Conservation, Beijing Forestry University, Beijing 100083, China \\ 2 Upper and Middle Yellow River Bureau, Yellow River Conservancy Commission, Shanxi 710000, China
}

\begin{abstract}
Based on the high-density observation method of soil moisture on natural slopes, this study clarifies the dynamic characteristics, spatial and temporal stability, and influencing factors of soil moisture on the natural slopes of Platycladus orientalis in Beijing mountainous areas. It is necessary to provide a basis for the assessment of the impact of ecological restoration on hydrology and water resources in the earth-rock mountainous area of northern China. Taking the slope ( $40 \mathrm{~m} \times$ $50 \mathrm{~m}$ ) of Platycladus orientalis forest land in Beijing Jiufeng National Forest Park as the research object, 30 measuring points in the natural slope were measured by Diviner 2000 and the soil water content (SWC) above gravel layer was observed from August 2014 to March 2016. The results show that the soil water storage (SWS) has visibly seasonal variation characteristics and is consistent with the quantitative value change trend; the average SWC of different soil layers is in intermediate variability and the SWC variability decreases with increase in SWC. Soil moisture has a high time stability during the entire observation period. The No.2 measuring point located on the horizontal slope is the most representative of the average soil moisture in the study area. With the increase of the distance from the tree, the SWS gradually increase. In spring, summer, and autumn, the SWS at the distance of $0.5 \mathrm{~m}$ and $1.5 \mathrm{~m}$ from the tree is significantly different
\end{abstract}

基金项目: 北京林业大学科技创新计划项目(2017ZY02)

收稿日期: 2020-06-27; 网络出版日期:2021-01-27

* 通讯作者 Corresponding author.E-mail: xinzhongbao@126.com 
$(P<0.05)$. SWS of the horizontal level is significantly greater than SWS of the steep slope $(P<0.05)$, and the SWS on the downslope in summer and autumn is significantly lower than that of the upslope $(P<0.05)$. Soil and water conservation engineering measures have important influence on the SWC distribution pattern on the slope.

Key Words : Beijing mountain area; soil moisture; temporal stability ; seasonal dynamics ; micro-topography

土壤水分参与地表径流、人渗、地下水补给、溶质运移、植物蒸腾以及地表的质量和能量收支等过程,它是 控制一系列水文和生态过程的关键变量 ${ }^{[1-3]}$ 。土壤水分也是限制植被生长的关键因素 ${ }^{[4]}$, 在很大程度上决定 了生态系统的组织和功能 ${ }^{[5]}$ 。由于降水量、土地利用和管理、景观和土壤水文特性的异质性,土壤水分与时 间有着复杂的关系 ${ }^{[3]}$, 土壤水分在时间上具有变异性, 因此了解这种变化对于更深人理解相关过程至关 重要。

Vachaud 等 ${ }^{[6]}$ 首次提出时间稳定性的概念, 指出空间上的某些观测点的土壤水分在时间上表现为持续偏 高或持续偏低, 比如这些观测点在某一时间的土壤含水量很低,那么它们在另一时间也保持着很低的含水量, 即其空间变异格局表现出随时间持续不变或变化甚微的稳定性特征,这些观测点能够代表研究区域的平均土 壤水分状况。因此通过分析土壤水分的时间稳定性,找出观测样地具有稳定代表性点,这样可以减少土壤水 分观测测点, 同时又能准确获取土壤水分状况。时间稳定性的概念已经被引用于许多土壤水分研究中, 以验 证和校准遥感土壤水分数据 ${ }^{[7-9]}$, 用时间稳定性的代表性点来确定研究区的平均土壤水分 ${ }^{[10-13]}$,并且借助代 表性点可以用实测数据校正水文模型 ${ }^{[14]}$ 。此外,将时间稳定性应用于预测模型,有助于得到完整的土壤水分 时间序列数据 ${ }^{[15]}$ 。国内土壤水分时间稳定性研究主要是在黄土高原地 ( $^{[16-17]}$ 、荒漠化地区 ${ }^{[18-19]}$ 。北方土石 山区水资源短缺、气候易旱、年均降水不均, 土层癐薄、岩石裸露、坡度陡,土壤水分观测工作相对薄弱,当前还 缺乏这一区域土壤水分稳定性的研究。

土壤特性、地形、土地利用、植被,降雨和时间等因素综合影响土壤水分。Feng 等 ${ }^{[20]}$ 认为影响土壤水分的 主导因素在不同空间尺度上不同,在小流域尺度下主要为土地利用类型、坡度、相对高程,在流域尺度下主要 为坡位、植被覆盖度、坡度 ; 刘宇等 ${ }^{[21]}$ 发现样点离树距离和坡度是影响雨前土壤水分变化的主导因素, 而在雨 后则主要受叶面积指数和枯落物厚度的影响。1988-2000 年北京山区植被严重退化,2000 年以后采取大量 的生态恢复措施 ${ }^{[22]}$, 其中水保工程措施作为生态修复的重要手段 ${ }^{[23]}$, 尤其是坡面整地工程 ${ }^{[24-25]}$, 对于北京山 区生态环境的改善十分重要。

北京山区作为北京的水源涵养区,直接影响首都的生态环境建设与可持续发展。目前, 北京山区土壤水 分方面已有一些研究,但多关注土壤水分动态变化过程以及对气象因子的响应, 观测点多是一个坡面上中下 3 个观测点位, 当前在北京山区还缺乏自然坡面尺度高密度布点系统观测研究。侧柏 (Platycladus orientalis) 是北京山区分布范围较广的典型针叶人工树种, 了解其典型树种的坡面土壤水分的动态变化、时间稳定性及 影响因素具有重要意义。本研究以北京西山鹑峰国家森林公园典型侧柏林坡面为对象,通过自然坡面尺度高 密度布点的土壤水分系统观测, 旨在掌握北京山区坡面土壤水分时间动态变化特征,揭示坡面土壤水分时间 稳定性特征及其对多因素的响应过程,提升对北京山区坡面土壤水分时空动态及其影响因素的认识, 为北京 山区森林生态系统涵养水源效益评估和林水关系精细化管理提供参考。

\section{1 材料与方法}

\section{1 研究区概况}

实验地位于北京林业大学教学实验林场-西山鹑峰国家森林公园, 北纬 $39^{\circ} 54^{\prime}$, 东经 $116^{\circ} 28^{\prime}$ 。气候类型 属于华北暖温带半湿润半干旱大陆性季风气候区, 年平均气温 $11.6{ }^{\circ} \mathrm{C}$, 最高气温 $41.6{ }^{\circ} \mathrm{C}$, 最低气温 $-19.6{ }^{\circ} \mathrm{C}$, 年蒸发量为 $1900 \mathrm{~mm}$, 年平均降雨量在 600-700 mm,多集中在 7-9 月份,占全年降水量的 70\% 以上。林场 
内部山地高差较大, 海拔高度在 100 - $1153 \mathrm{~m}$ 之间,地形复杂多样, 山地坡度以 $15^{\circ}$ - $35^{\circ}$ 为主, 占山地总面积 的 $70.4 \%$ 。研究区土壤类型为黄土 ${ }^{[26]}$, 土层较薄, 厚度为 $50-70 \mathrm{~cm}$, 较深土层土壤多为砾石层和母质层。其 植被覆盖率超过 $96 \%$, 主要的植被类型为人工林和天然次生林, 其中人工林有侧柏 (Platycladus orientalis)、油 松( Pinus tabulaeformis)、落叶松(Larixgmelinii)、栓皮栋( Quercus variabilis) 等。

本研究以鹑峰国家森林公园侧柏林坡面 $(40 \mathrm{~m} \times 50 \mathrm{~m}$ ) 样地为研究对象,包括从坡顶到坡底整个坡面,于 2014 年 6 月 5 日至 6 月 8 日进行了地形测量和植被调查工作,调查坡面样地海拔在 158.1 - $178.6 \mathrm{~m}$ 之间,坡 度多在 $15^{\circ}$ 以上, 经统计不同高程的平均坡度,样地可以分为水平阶、陡坎、缓坡地、陡坡地 4 种微地形。样地 为侧柏纯林, 共林木 289 株, 林分密度 1445 株 $/ \mathrm{hm}^{2}$, 平均株间距为 $2.6 \mathrm{~m}$, 其中, 胸径 $>9 \mathrm{~cm}$ 的平均株间距为 $3.0 \mathrm{~m}$,已经郁闭, 林下灌木没有很好地发育, 只在坡面中下部零星分布孩儿拳头( Grewia biloba)、荆条( Vitex negundo)、构树 (Broussonetia papyrifera) 等灌木, 基本无草本分布,林下枯落物亦较少。

\section{2 样点布设与数据采集}

研究是从山脊向下到沟缘的整个自然坡面, 坡面宽长为 $40 \mathrm{~m} \times 50 \mathrm{~m}$,顺等高线方向布设 3-6 个重复观 测点位, 顺坡布设 5 个条带, 每条条带布设 4-7 个观测点位, 另外考虑了树木根系对土壤水分的影响, 尽可能 在同一等高线上布设不同离树距离 $(0.5 \mathrm{~m} 、 1.0 \mathrm{~m} 、 1.5 \mathrm{~m})$ 观测管各一个。坡面受人工整地影响, 土层深度在 坡面各个位置有所差别。水平阶和下部局部平缓的地方土层较厚, 土壤水分观测深度为 $70 \mathrm{~cm}$; 坡面上部陡 坎处和坡下陡坡地上土层相对较薄, 土壤水分的观测深度为 $50 \mathrm{~cm}$ 或 $60 \mathrm{~cm}$ 。其观测深度为母质层以上, 包括 整个土壤层。观测深度为 $50 \mathrm{~cm} 、 60 \mathrm{~cm} 、 70 \mathrm{~cm}$ 分别有 10 个、4 个和 16 个, 共布设 30 个观测点位, 观测点的平 均距离为 $5.7 \mathrm{~m}$,于 2014 年 6 月 14 号完成野外布设工作 (表 1, 图 1)。本实验 SWC 的测定基于 Diviner 2000

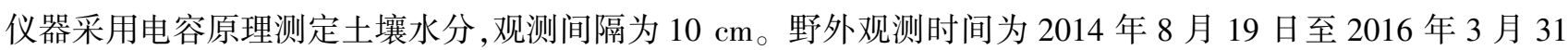
日, 共观测 38 次, 每月至少进行一次观测, 在非汛期通常以月、半月间隔观测, 而汛期观测间隔加密, 大致 $5 \mathrm{~d}$ 观测一次。

表 1 土壤水分观测点的分布设计

Table 1 Distribution design of soil moisture observation points

\begin{tabular}{|c|c|c|c|c|c|c|c|c|c|c|c|}
\hline $\begin{array}{c}\text { 观测点编号 } \\
\text { Observation } \\
\text { point number }\end{array}$ & $\begin{array}{c}\text { 微地形 } \\
\text { Micro- } \\
\text { topography }\end{array}$ & $\begin{array}{c}\text { 坡位 } \\
\text { Slope } \\
\text { position }\end{array}$ & $\begin{array}{c}\text { 距树 } \\
\text { Distance } \\
\text { from } \\
\text { tree/cm }\end{array}$ & $\begin{array}{c}\text { 观测深度 } \\
\text { Observation } \\
\text { depth /cm }\end{array}$ & $\begin{array}{c}\text { 海拔 } \\
\text { Altitude/m }\end{array}$ & $\begin{array}{c}\text { 观测点编号 } \\
\text { Observation } \\
\text { point number }\end{array}$ & $\begin{array}{c}\text { 微地形 } \\
\text { Micro- } \\
\text { topography }\end{array}$ & $\begin{array}{c}\text { 坡位 } \\
\text { Slope } \\
\text { position }\end{array}$ & $\begin{array}{c}\text { 距树 } \\
\text { Distance } \\
\text { from } \\
\text { tree/cm }\end{array}$ & $\begin{array}{c}\text { 观测深度 } \\
\text { Observation } \\
\text { depth /cm }\end{array}$ & $\begin{array}{c}\text { 海拔 } \\
\text { Altitude/m }\end{array}$ \\
\hline 1 & 水平阶 & 上坡 & 50 & 60 & 176.2 & 16 & 缓坡地 & 中坡 & 50 & 60 & 169.1 \\
\hline 2 & 水平阶 & 上坡 & 150 & 70 & 176.4 & 17 & 缓坡地 & 中坡 & 100 & 70 & 169.0 \\
\hline 3 & 水平阶 & 上坡 & 50 & 70 & 176.7 & 18 & 缓坡地 & 中坡 & 100 & 70 & 166.2 \\
\hline 4 & 水平阶 & 上坡 & 150 & 70 & 174.7 & 19 & 陡坎 & 中坡 & 150 & 50 & 167.7 \\
\hline 5 & 水平阶 & 上坡 & 100 & 70 & 175.2 & 20 & 陡坎 & 中坡 & 50 & 50 & 168.1 \\
\hline 6 & 水平阶 & 上坡 & 50 & 70 & 175.8 & 21 & 陡坡地 & 下坡 & 100 & 50 & 168.1 \\
\hline 7 & 水平阶 & 上坡 & 100 & 70 & 173.0 & 22 & 陡坡地 & 下坡 & 100 & 50 & 166.0 \\
\hline 8 & 水平阶 & 上坡 & 150 & 70 & 173.7 & 23 & 缓坡地 & 下坡 & 100 & 70 & 164.2 \\
\hline 9 & 水平阶 & 上坡 & 50 & 50 & 174.2 & 24 & 陡坡地 & 下坡 & 50 & 60 & 164.4 \\
\hline 10 & 水平阶 & 上坡 & 150 & 50 & 171.6 & 25 & 陡坡地 & 下坡 & 100 & 50 & 162.6 \\
\hline 11 & 水平阶 & 中坡 & 150 & 70 & 171.6 & 26 & 陡坡地 & 下坡 & 100 & 70 & 162.7 \\
\hline 12 & 水平阶 & 中坡 & 100 & 50 & 172.1 & 27 & 缓坡地 & 下坡 & 100 & 70 & 162.2 \\
\hline 13 & 陡坎 & 中坡 & 100 & 50 & 170.2 & 28 & 缓坡地 & 下坡 & 150 & 70 & 161.4 \\
\hline 14 & 缓坡地 & 中坡 & 100 & 50 & 170.5 & 29 & 缓坡地 & 下坡 & 100 & 70 & 160.2 \\
\hline 15 & 水平阶 & 中坡 & 50 & 70 & 171.9 & 30 & 缓坡地 & 下坡 & 100 & 60 & 159.5 \\
\hline
\end{tabular}

1.3 分析方法

(1) 土壤蓄水量比土壤含水量更能直观的反映研究区域土壤水分的供给能力。其转公式 ${ }^{[27]}$ 如下: 


$$
\mathrm{SWS}=\theta \cdot h \cdot 10^{-1}
$$

式中, $\mathrm{SWS}$ 是土壤蓄水量 $(\mathrm{mm}), \theta$ 是土壤体积含水量 $(\%), h$ 为土层厚度 $(\mathrm{cm})$ 。

(2) 经典统计

随机变量的离散程度, 即变异性的大小, 可用变异 系数 $\mathrm{CV}$ 的大小来反映, 计算公式 ${ }^{[27]}$ 为:

$$
C V=\frac{s}{m}
$$

式中, $m$ 为样本平均值; $s$ 为标准差。根据变量程度分 级: $C V<10 \%$ 为弱变异性; $10 \% \leqslant C V \leqslant 100 \%$ 为中等变异 性; $C V \geqslant 100 \%$ 为强变异性。

(3) 非参数性 Spearman 秩相关检验 ${ }^{[6]}$

采用非参数性 Spearman 秩相关检验, 可以检验不 同时间小区 SWC 空间格局的一致性或相似性。 Spearman 秩相关系数 $r_{s}$, 通过下式来定义:

$$
r_{s}=1-\frac{6 \sum_{j=1}^{n}\left(R_{i j}-R_{i j^{\prime}}\right)}{n\left(n^{2}-1\right)}
$$

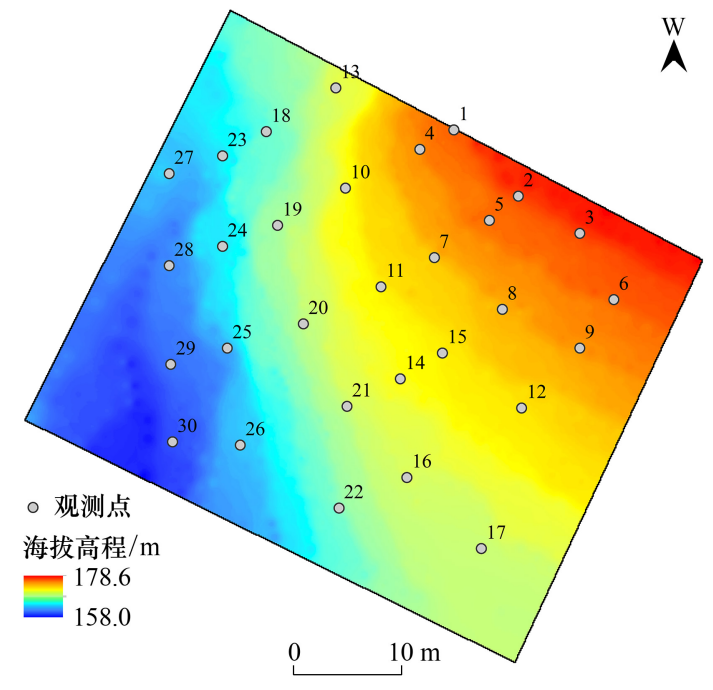

图 1 土壤水分观测点空间分布

Fig.1 Spatial distribution of soil moisture observation points

式中, $n$ 为实验小区内测点的数目, $R_{i j}$ 为测点 $i$ 在时间 $j$ 的秩, $R_{i j^{\prime}}$ 为测点 $i$ 在时间 $j^{\prime}$ 的秩。 $r_{s}$ 值越接近 1 , 说明 土壤水分分时间稳定性越强。

(4) 相对偏差法 ${ }^{[6]}$ 和时间稳定性指数 $\left(\operatorname{ITS}_{\mathrm{i}}\right)^{[28]}$

$$
\begin{aligned}
& \delta_{i j}=\frac{\theta_{i j}-\bar{\theta}_{j}}{\bar{\theta}_{j}} \\
& \bar{\theta}_{j}=\frac{1}{m} \sum_{i=1}^{m} \theta_{i j} \\
& \bar{\delta}_{i}=\frac{1}{n} \sum_{j=1}^{n} \delta_{i j} \\
& \sigma\left(\delta_{i}\right)=\sqrt{\frac{1}{n-1} \sum_{j=1}^{n}\left(\delta_{i j}-\bar{\delta}_{i}\right)^{2}} \\
& \operatorname{ITS}_{i}=\sqrt{\bar{\delta}_{i}{ }^{2}+\sigma\left(\delta_{i}\right)^{2}}
\end{aligned}
$$

式中, $j$ 为测定时间, $i$ 为测点位置, $\delta_{i j} 、 \theta_{i j}$ 分别为时间 $j$ 时测点 $i$ 处的相对偏差、土壤含水量, $n$ 为土壤水分观测次 数, $m$ 为观测点的总数, $\bar{j}_{j}$ 为研究区时间 $j$ 的所有测量值的均值, $\bar{\delta}_{i} 、 \sigma\left(\delta_{i}\right)$ 分别为所有测量时间 $j$ 内各测量点的土壤 含水量的平均相对偏差 (MDR)、平均相对偏差的标准差。平均相对偏差的标准差越小, 则时间稳定性越高。通常选 择平均相对偏差接近于 0 且平均相对偏差的标准差较小的测点, 来估计研究区的平均土壤含水量 ${ }^{[27]}$ 。

\section{2 结果}

\section{1 土壤水分动态变化}

土壤水分动态变化因季节变化而变化。冬季降雨事件较少, 土壤蓄水量 (SWS) 降到最低水平, 且整个冬 季基本变化不大, 春季 SWS 有较小幅度的下降, 随着夏季雨水补给, SWS 逐渐攀升, 秋季 9-10 月达到峰值, 进人秋季后 SWS 出现回落, 平均 SWS 与降水量基本保持一致, 土壤水分呈现明显的季节性变化(图 2)。 $2014 、 2015$ 年 12 月 SWS 分别为 $(78.2 \pm 24.6) \mathrm{mm} 、(159.2 \pm 37.1) \mathrm{mm}, 2015$ 年比 2014 年增加了 $103.7 \%$, 在观 
测期内该时段增加量最大。

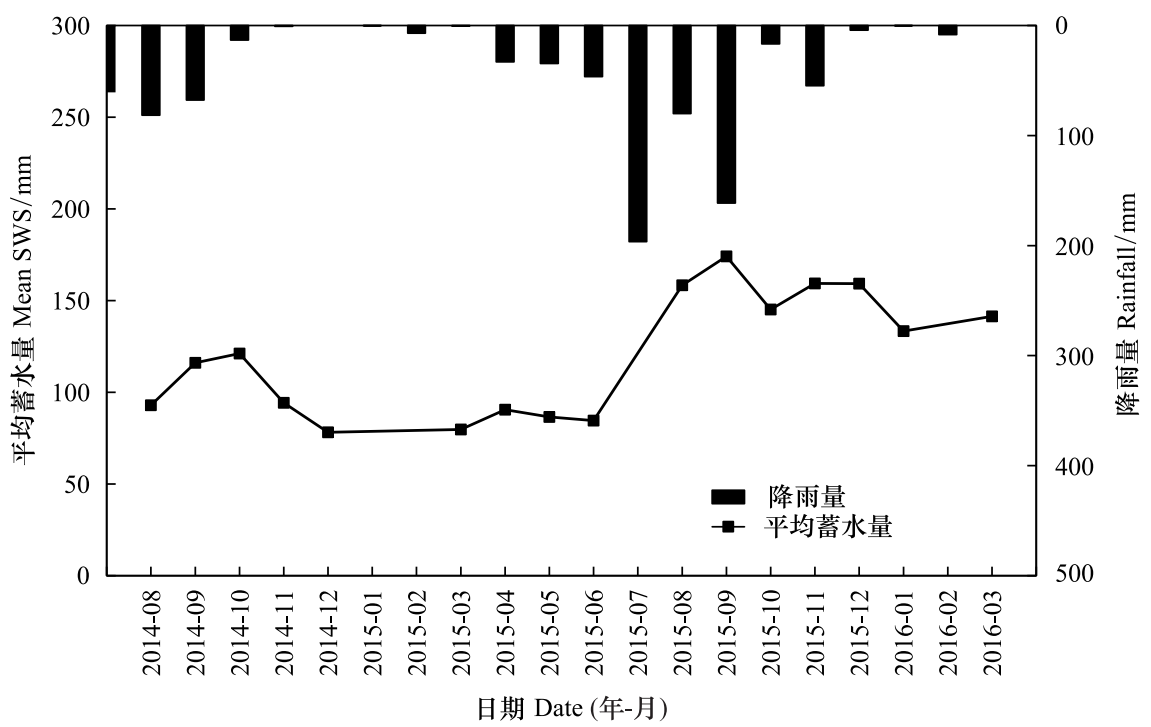

图 2 降雨量与月平均 SWS 图

Fig.2 Rainfall and monthly mean SWS

SWS: 土壤蓄水量 Soil water storage

整个监测期内土壤含水量 $(\mathrm{SWC}$ ) 随着土壤深度的增加而增加 (表 2)。0-10 $\mathrm{cm}$ 土层的平均 $\mathrm{SWC}$ 最低, 为 $12.7 \pm 7.9 \%$; $60-70 \mathrm{~cm}$ 土层的平均 SWC 最高, 为 $26.4 \pm 8.9 \% ; 10-20 \mathrm{~cm}$ 土层土壤水分快速增加, 随土层的 加深土壤水分增加趋势明显, 但绝对增量不大, 变幅只有 $4.6 \% ; 0-10 \mathrm{~cm} 、 10-20 \mathrm{~cm} 、 20-40 \mathrm{~cm} 、 40-60 \mathrm{~cm}$ 、 60-70 cm 土层之间平均 SWC 有显著性差异 $(P<0.05)$ 。全剖面 SWC 的平均变异系数为 $38.4 \%$, 表层 $(0-10$ $\mathrm{cm}) \mathrm{SWC}$ 的变异系数最大 $(62.2 \%), 10-20 \mathrm{~cm}$ 土层土壤水分的变异系数迅速减小到 $33 \%$, 研究区不同土层 的含水量均处于中等变异。平均 SWC 与变异系数的相关性 (图 3) 表明,平均 SWC 量的平均值与变异系数呈 显著的线性相关, 当研究区的 SWC 较高时, SWC 的变异性较低。

表 2 不同土层平均 SWC 的统计分析

Table 2 Statistical analysis of mean SWC in different soil layers

\begin{tabular}{lccc}
\hline $\begin{array}{c}\text { 土层 } \\
\text { Soil layer/cm }\end{array}$ & $\begin{array}{c}\text { 均值 } \\
\text { Mean } / \%\end{array}$ & $\begin{array}{c}\text { 标准差 } \\
\text { Standard deviation/\% }\end{array}$ & $\begin{array}{c}\text { 变异系数 } \\
\text { Coefficient of variation/\% }\end{array}$ \\
\hline $0-10$ & $12.7 \mathrm{e}$ & 7.9 & 62.2 \\
$10-20$ & $21.8 \mathrm{~d}$ & 7.2 & 33.0 \\
$20-30$ & $23.4 \mathrm{c}$ & 7.5 & 32.1 \\
$30-40$ & $23.1 \mathrm{c}$ & 8.1 & 35.1 \\
$40-50$ & $24.8 \mathrm{~b}$ & 8.8 & 35.5 \\
$50-60$ & $24.6 \mathrm{~b}$ & 9.1 & 37.0 \\
$60-70$ & $26.4 \mathrm{a}$ & 8.9 & 33.7 \\
\hline
\end{tabular}

同列不同字母代表差异显著 $(P<0.05)$; $\mathrm{CV}$ :变异系数 Coefficient of variation; SWC: 土壤含水量 Soil water content

\section{2 土壤水分时间稳定性}

研究区在整个观测期内不同时间段土壤水分含量的 Spearman 秩相关系数矩阵显示 (表 3),Spearman 秩 相关系数在 0.01 水平上均显著相关, 说明研究区内 SWC 在整个观测内都具有较高的时间稳定性。秩相关系 数大于 0.8 的比列为 $56.6 \%$,大于 0.7 的比列为 $86.0 \%$, 可以看出绝大部分时段基本达到 0.7 以上。

将 SWC 的平均相对偏差 (MRD) 由小到大排序 (图 4), 描述其时间稳定性特征。SWC 的 MRD 变化范围 为 $-28.9 \%-52.7 \%$, 变幅为 $81.6 \%$, 可以看出 $\mathrm{MRD}$ 的波动范围较大。平均相对偏差的标准差介于 $3.8 \%-$ 


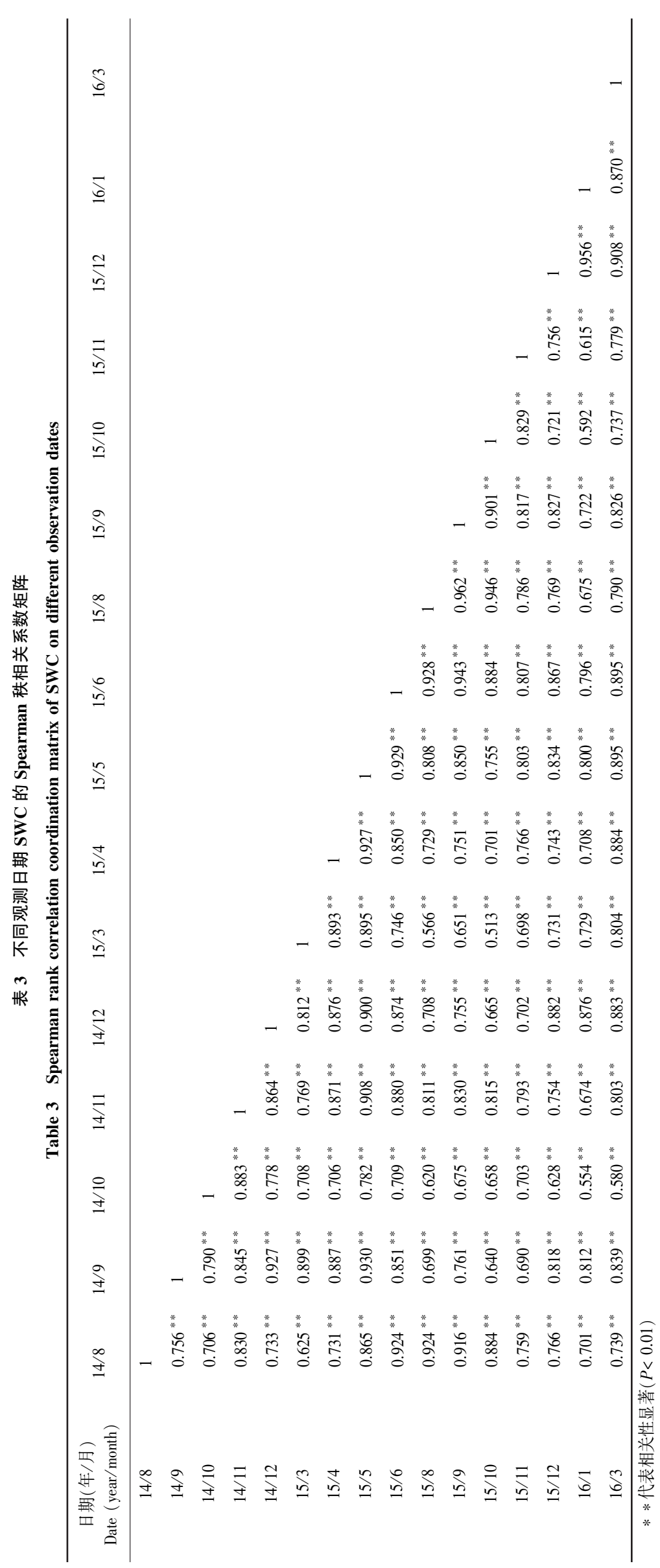


16.9\% 之间, 大部分测点平均相对偏差的标准差小于 $10 \%$, 且平均相对偏差的标准差的平均值为 $8.2 \%$, 说明 大部分测点土壤水分时间稳定性较高。基于 MRD 接近 于 0 (在 $\pm 5 \%$ 之内视为接近 0 ) 原则, 可选择代表性测点 来估计研究区的平均土壤水分 ${ }^{[27,29]}$ 。从图 5 可以看出 能预测全剖面 SWC 的点共有 7 个,这些代表性点位于 坡面最上部水平阶的 $2 、 4 、 5$ 号观测点, 中下部缓坡地的 29 号观测点, 陡坡地的 $21 、 22 、 24$ 号观测点。根据时间 稳定性指数 (ITS) 值越小土壤水分的时间稳定性就越 强的原则 ${ }^{[27]}$,计算 7 个代表性点的 ITS, 发现 2 号观测 点最能代表研究区的平均土壤水分。样点 2 的 SWC 与 研究区平均 SWC 显著相关(图 5), 能代表研究区的平 均土壤水分。

\section{3 土壤水分影响因素}

坡面土壤水分动态变化以及空间分布格局,受气

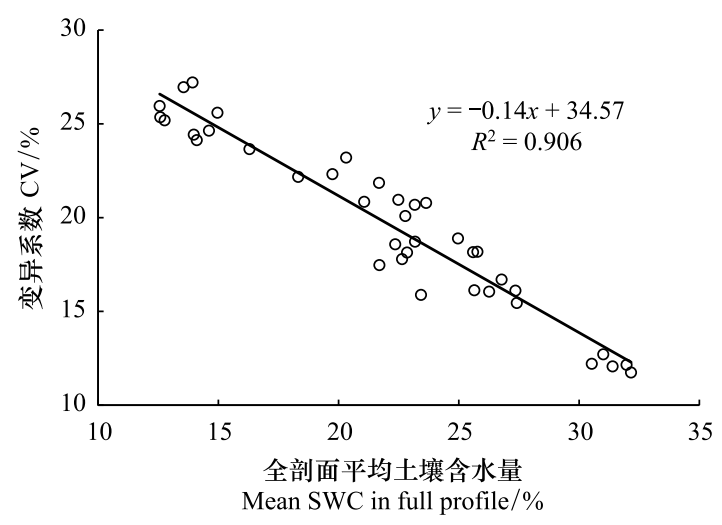

图 3 平均 SWC 与变异系数的关系 $(2014$ 年 8 月 19 日一-2016 年 3 月 31 日)

Fig.3 Relationship between mean SWC and CV (August 19, 2014-March 31, 2016)

$\mathrm{CV}$ : Coefficient of variation 候、地形、植被以及采样方式等多种因素综合影 响 ${ }^{[30-31]}$ 。这部分重点从坡位、微地形和观测点布置方式三个方面对坡面土壤水分空间变化的影响因素进行 分析(表 4)。

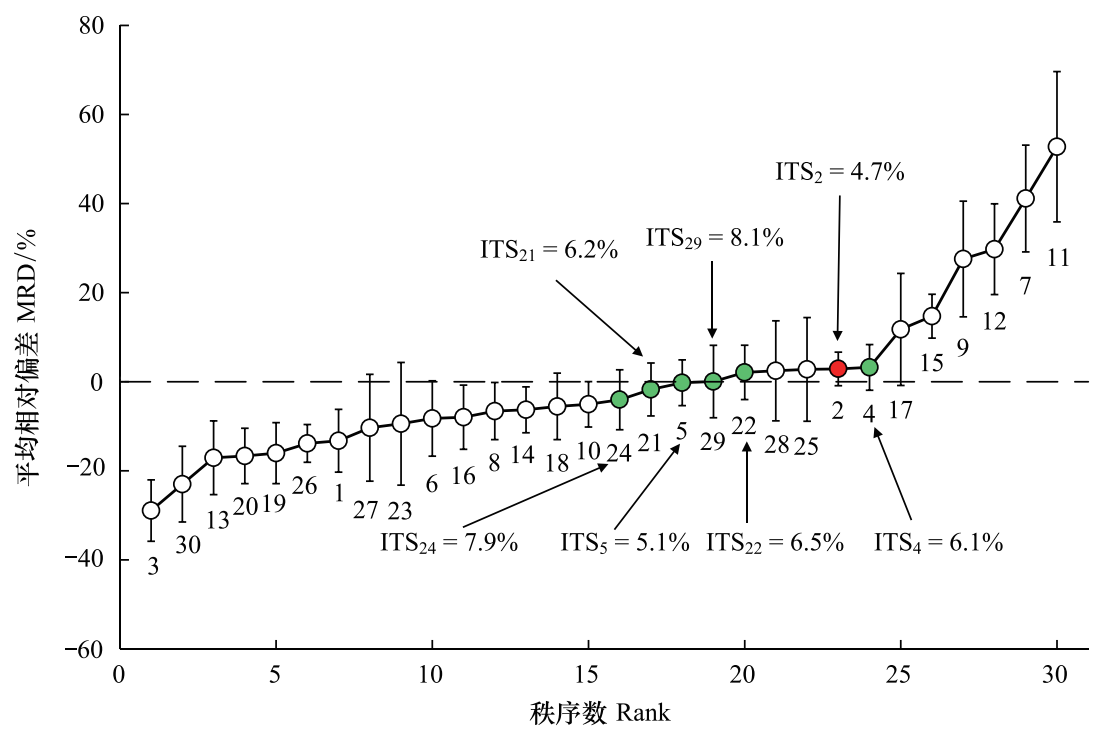

图 $4 \mathrm{SWC}$ 的平均相对偏差和代表性点的时间稳定性常数

Fig.4 MRD of SWC and ITS of representative locations

MRD: Mean relative deviation; ITF: Index of time stability

(1) 微地形影响。结果表明,水平阶、缓坡地、陡坡地、陡坎 4 种微地形下 SWS 存在明显差异 $(P<0.05)$, 水平 阶的 SWS 显著高于陡坎,水平阶在整个观测期内的平均蓄水量春、夏、秋、冬的 SWS 分别为 $(96.3 \pm 31.8) \mathrm{mm}$ 、 $(167.7 \pm 53.3) \mathrm{mm} 、(182.6 \pm 43.8) \mathrm{mm} 、(159.7 \pm 42.0) \mathrm{mm}$, 显著高于陡坎的 $S W S$, 分别高出 $40.3 \mathrm{~mm} 、 71.0 \mathrm{~mm} 、$ $72.9 \mathrm{~mm} 、 58.9 \mathrm{~mm}$,微地形对坡面 SWS 具有明显的影响,水平阶对土壤水分具有良好保持作用。

(2) 坡位。坡上与坡中 SWS 差异不显著,坡上和坡中与坡下之间 SWS 存在差异。春季和冬季上坡位与 下坡位之间 SWS 不存在显著差异,但其他 2 个季节上坡位显著高于下坡位 $(P<0.05)$ 。夏、秋二个季节上坡 
位的 SWS 分别为 $(158.8 \pm 48.8) \mathrm{mm} 、(173.6 \pm 39.4) \mathrm{mm}$, 下坡位的 SWS 分别为 $(138.3 \pm 43.7) \mathrm{mm} 、(152.5 \pm 33.0)$ $\mathrm{mm}$,上坡位比下坡分别高出 $20.5 \mathrm{~mm} 、 21.1 \mathrm{~mm}$ 。

(3) 观测点离树距离。在与土壤水分观测点离树 距离为 $0.5 \mathrm{~m} 、 1.0 \mathrm{~m} 、 1.5 \mathrm{~m}$ 处时, 随着离树距离的增加, SWS 有逐渐增加的趋势。不同季节这种增加趋势的显 著程度不同, 冬季不同离树距离之间 SWS 增加不显著, 其他 3 个季节样点离树距离 $0.5 \mathrm{~m}$ 与 $1.5 \mathrm{~m}$ 之间的增加 趋势尤其显著 $(P<0.05)$ 。春、夏、秋样点离树 $0.5 \mathrm{~m}$ 处 SWS 分别为 $75.318 .6 \mathrm{~mm} 、(142.8 \pm 44.4) \mathrm{mm} 、(155.0 \pm$ $34.9) \mathrm{mm}, 1.5 \mathrm{~m}$ 处 $\mathrm{SWS}$ 分别为 $(95.6 \pm 34.9) \mathrm{mm}$ 、 $(168.9 \pm 59.0) \mathrm{mm} 、(179.3 \pm 50.3) \mathrm{mm}$, 春、夏、秋季离树

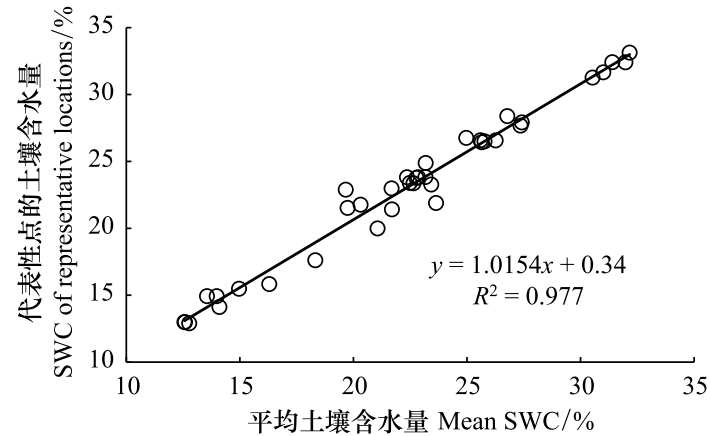

图 5 样地平均 SWC 与代表性点 2 的 SWC 的比较

Fig.5 Comparison between average SWC of observed plot and SWC of representative location 2 距离 $1.5 \mathrm{~m}$ 处比 0.5 处 SWS 分别增加了 $20.3 \mathrm{~mm} 、 26.1$ $\mathrm{mm} 、 24.3 \mathrm{~mm}$ 。

表 42015 年 3 月至 2016 年 3 月影响因素下 SWS 的季节性变化

Table 4 Seasonal variation of SWC under influencing factors from March 2015 to March 2016

\begin{tabular}{|c|c|c|c|c|c|c|c|c|c|}
\hline \multirow[b]{2}{*}{$\begin{array}{c}\text { 影响因素 } \\
\text { Influencing factors }\end{array}$} & & \multicolumn{2}{|c|}{ 春季 Spring } & \multicolumn{2}{|c|}{ 夏季 Summer } & \multicolumn{2}{|c|}{ 秋季 Autumn } & \multicolumn{2}{|c|}{ 冬季 Winter } \\
\hline & & $\begin{array}{c}\text { 均值 } \\
\text { Mean } / \mathrm{mm}\end{array}$ & $\begin{array}{c}\text { 标准差 } \\
\text { Standard } \\
\text { deviation/\% }\end{array}$ & $\begin{array}{c}\text { 均值 } \\
\text { Mean } / \mathrm{mm}\end{array}$ & $\begin{array}{c}\text { 标准差 } \\
\text { Standard } \\
\text { deviation/\% }\end{array}$ & $\begin{array}{c}\text { 均值 } \\
\text { Mean/mm }\end{array}$ & $\begin{array}{c}\text { 标准差 } \\
\text { Standard } \\
\text { deviation/\% }\end{array}$ & $\begin{array}{c}\text { 均值 } \\
\text { Mean/mm }\end{array}$ & $\begin{array}{c}\text { 标准差 } \\
\text { Standard } \\
\text { deviation/\% }\end{array}$ \\
\hline 坡位 & 上坡 & $88.5 \mathrm{a}$ & 27.5 & $158.8 \mathrm{a}$ & 48.8 & $173.6 \mathrm{a}$ & 39.4 & 151.1a & 37.5 \\
\hline \multirow[t]{2}{*}{ Slope position } & 中坡 & $84.3 \mathrm{a}$ & 33.8 & $148.2 \mathrm{ab}$ & 61.5 & $164.7 \mathrm{a}$ & 53.7 & $144.6 \mathrm{a}$ & 47.7 \\
\hline & 下坡 & $84.1 \mathrm{a}$ & 18.3 & $138.3 \mathrm{~b}$ & 43.7 & $152.5 \mathrm{~b}$ & 33.0 & $130.3 \mathrm{a}$ & 28.5 \\
\hline 微地形 & 水平阶 & $96.3 \mathrm{a}$ & 31.8 & $167.7 \mathrm{a}$ & 53.3 & $182.6 \mathrm{a}$ & 43.8 & $159.7 \mathrm{a}$ & 42.0 \\
\hline \multirow[t]{3}{*}{ Micro-topography } & 缓坡地 & $87.0 \mathrm{ab}$ & 19.7 & $147.7 \mathrm{ab}$ & 48.9 & $165.8 \mathrm{~b}$ & 38.2 & 138.6ab & 35.7 \\
\hline & 陡坡地 & $73.8 \mathrm{~b}$ & 11.3 & $129.4 b$ & 37.3 & $141.1 \mathrm{c}$ & 23.1 & $126.8 \mathrm{~b}$ & 17.6 \\
\hline & 陡坎 & $56.0 \mathrm{c}$ & 8.1 & $96.7 \mathrm{c}$ & 29.8 & $109.7 \mathrm{~d}$ & 15.1 & $100.8 \mathrm{c}$ & 11.7 \\
\hline 离树 & 0.5 & $75.3 \mathrm{~b}$ & 18.6 & $142.8 \mathrm{~b}$ & 44.4 & $155.0 \mathrm{~b}$ & 34.9 & $133.6 \mathrm{a}$ & 28.3 \\
\hline \multirow[t]{2}{*}{ Distance from tree/m } & 1 & $86.6 \mathrm{ab}$ & 25.5 & $142.6 \mathrm{~b}$ & 51.2 & $160.9 \mathrm{~b}$ & 42.8 & $140.7 \mathrm{a}$ & 38.9 \\
\hline & 1.5 & 95.6a & 34.9 & $168.9 \mathrm{a}$ & 59.0 & $179.3 \mathrm{a}$ & 50.3 & $154.4 \mathrm{a}$ & 48.4 \\
\hline
\end{tabular}

相同影响因素下的同列不同字母代表差异显著 $(P<0.05)$

\section{3 讨论}

降水对坡面土壤蓄水量影响。2015 年 8-12 月的 SWS 比 2014 年同期增加 58.4\%,2016 年 3 月比 2015 年 3 月的 SWS 增加了 77.2\%,2016 年 3 月甚至比 2014 年雨季的 SWS 还高。由于森林对降水具有截留作用, 使降雨强度减弱, 而降雨前土壤量水分的蓄存量少, 因此前期降雨量不足引起坡面产流 ${ }^{[32]}$, 延缓地表径流的 汇流, 从而增加降雨人渗补给的历时,使土壤得到更多的水分补给 ${ }^{[33]}$ 。Wang 等 ${ }^{[34]}$ 对 3 种人工林进行长期土 壤水分定位观测发现林地具有明显土壤水分累积特征,与本研究结果相似。2016 年 3 月植被已经进人休眠 或枯死, 此时段主要是土壤蒸发影响土壤水分, 而侧柏为常绿树种,林冠层对土壤有良好的遮阴,因此能较好 的减少土壤蒸发 ${ }^{[26]}$, 又加上 2015 年雨季充分的雨水补给,所以此时段的 SWS 较高。表层土壤更容易受到环 境的影响,随时间变化会有较大的波动,随着土壤深度的加深含水量逐渐增加,其变异系数减小。全剖面土壤 水分的变异系数均属于中等变异,对于其他不同地区和不同土地利用方式也得出来相似的结论 ${ }^{[29,35-36]}$ 。由于 表层土壤受太阳辐射、降水、风等外界环境的影响, 随着深度的增加,外界环境对土壤水分的影响逐渐减 弱 $^{[37]}$ 。其次侧柏属于浅根性树种, 其根系分布在表层 ${ }^{[38]}$, 大部分集中在 $0-60 \mathrm{~cm}$ 土层中 ${ }^{[39-40]}$, 主要利用 
10-30 $\mathrm{cm}$ 土层的土壤水分 ${ }^{[41-42]}$, 因此研究区土壤水分在时间上的离散程度较大。研究区土壤水分与变异系 数之间呈负相关,这与 Brocca 等 ${ }^{[43]}$ 和白一茹等 ${ }^{[44]}$ 的研究结果相同。

自然坡面土壤水分时间稳定性较好。研究区内土壤水分具有较好的时间稳定性,大部分测点 Spearman 秩相关系数均达到 0.7 以上且相关性极显著。潘颜霞等 ${ }^{[45]}$ 研究荒漠人工固沙植被区浅层土壤 $(0-30 \mathrm{~cm})$ 土 壤水分、赵文举等 ${ }^{[36]}$ 研究压砂地 $0-20 \mathrm{~cm}$ 土壤水分和 Zhao 等 ${ }^{[46]}$ 研究中国西北砾石覆盖区 $0-50 \mathrm{~cm}$ 土壤水 分均得出类似结论。而白一茹等 ${ }^{[44]}$ 研究黄土丘陵区粉壤土 $0-30 \mathrm{~cm}$ 土壤水分发现总体上采样坡面土壤水 分 Spearman 秩相关系数较小。Spearman 秩相关系数越接近 1 , 土壤水分时间稳定性强 ${ }^{[6]}$ 。这说明土壤水分 时间稳定性与所处的环境有关 ${ }^{[4]}$, 主要由土壤的结构与质地决定 ${ }^{[6]}$, 沙质土比粉壤土更能维持土壤水分的时 间稳定性 ${ }^{[48]}$ 。研究区 SWC 的 MRD 的波动范围较大这与白一茹、刘泽涁、He 等的研究结果相似 ${ }^{[29,44,49]}$, 与朱 绪超的研究结果相反 ${ }^{[35]}$ 。MRD 的波动范围与地形、气象、植被等因素有关。研究区 MRD 的波动范围较大原 因主要是, 研究坡面为林地, 雨季观测较多, 且冬季也进行了观测, 研究坡面进行了水土保持工程整地措施, 坡 度多在 $15^{\circ}$ 以上。这些原因共同导致平均相对偏差的波动范围较大。

微地形影响坡面土壤水分分布。微地形对坡面 SWS 影响显著,水平阶能有效的保持坡面土壤水分。水 土保持整地工程措施对土壤的静态分布和动态过程有一定的影响 ${ }^{[50]}$, 可以有效地提高土壤含水量 ${ }^{[51]}$ 。水平 阶作为北京山区重要的整地工程之一, 改变了微地貌, 增加了地表粗鉌度和起伏度, 截断了坡面径流, 使降雨 再分配 ${ }^{[52]}$, 而且其地势平坦,有利于土壤水分的下渗和积蓄。而阶地陡坎和陡坡地土层相对较薄, 且因坡度 较大, 排水条件良好, 不利于土壤水分蓄积。研究区坡上 SWS 大于坡下 SWS, 白一茹等 ${ }^{[33]}$ 研究黄土高原雨养 区坡面土壤水力学性质空间特征也得出相似的研究规律, 但也有研究 ${ }^{[54]}$ 发现 SWC 下坡位比上坡位高。一方 面, 本研究坡面经过整地, 水平阶阻断了地表径流和壤中流在重力作用下向下坡位运移,且具有良好保持土壤 水分的作用; 另一方面,这可能是由于上坡位和下坡土壤结构不同,白一茹等 ${ }^{[53]}$ 发现上坡位土壤结构比下坡 位好,坡面径流的冲刷作用下,使下坡位土壤颗粒较粗, 因此上坡位持水能力比下坡为好, 然而本研究并没测 定上坡位和下坡位土壤结构, 是否是因为土壤结构还需要进一步探讨。不同坡位之间 SWS 有差别, 但春季和 冬季上坡位与下坡位之间 SWS 差异不显著。本研究区春季和冬季降雨较少, 树冠冠层也能截留小的降雨事 件的降雨, 所以土壤水分的动态几乎不受小降雨事件的作用 ${ }^{[55]}$, 同时春季植被处于生长阶段, 因此植被削弱 了不同坡位 SWS 的差异性。由于侧柏根系分布量随离树干距离的增加而减少 ${ }^{[40]}$, 同时树冠冠层截留, 因此 土壤水分随着离树距离的增加呈逐渐增加的趋势。而冬季和夏季不同离树距离之间 SWS 无显著差异, 可能 是因为冬季植被休眠或枯死且降雨较少, 土壤水分的补给量与消耗量几乎平衡, 因此不同离树距离之间 SWS 无显著差异。

\section{4 结论}

本研究基于坡面尺度长时间序列多点监测的土壤水分数据, 探究坡面尺度土壤水分的时时空动态及其影 响因素。观测期内北京山区侧柏林土壤水分具有明显的季节特征、累积特征和垂直差异, 土壤水分与降雨量 基本保持一致, 土壤水分随深度加深而明显增加。坡面 30 个点位土壤水分在整个观测期内具有较高的时间 稳定性, 土壤水分含量的 Spearman 秩相关系数在 0.01 水平上均显著相关。结合 ITS 确定研究区平均土壤水 分的最佳代表点为位于上坡水平阶的 2 号观测点,通过对该点土壤水分的测量可以预测整个研究区的平均土 壤水分。微地形对土壤水分影响明显, 水平阶土壤蓄水量显著大于陡坎 $(P<0.05)$, 坡上与坡中 SWS 差异不 显著,夏、秋季下坡位土壤 SWS 显著高于上坡位 $(P<0.05)$, 因此水土保持整地工程能有效的保持坡面土壤 水分。

参考文献 (References) :

[ 1 ] Western A W, Blöschl B. On the spatial scaling of soil moisture. Journal of Hydrology, 1999, 217(3/4) : 203-224.

[ 2 ] Martínez-Fernández J, Ceballos A. Temporal stability of soil moisture in a large-field experiment in Spain. Soil Science Society of America Journal, 
2003, 67(6): 1647-1656.

[ 3 ] Heathman G C, Cosh M H, Merwade V, Han E. Multi-scale temporal stability analysis of surface and subsurface soil moisture within the Upper Cedar Creek Watershed, Indiana. CATENA, 2012, 95: 91-103.

[ 4 ] Berndtsson R, Nodomi K, Yasuda H, Persson T, Chen H S, Jinno K. Soil water and temperature patterns in an arid desert dune sand. Journal of Hydrology, 1996, 185(1/4) : 221-240.

[ 5 ] Rodriguez-Iturbe I, $D^{\prime}$ odorico P, Porporato A, Ridolfi L. On the spatial and temporal links between vegetation, climate, and soil moisture. Water Resources Research, 1999, 35(12): 3709-3722.

[ 6] Vachaud G, De Silans A P, Balabanis P, Vauclin M. Temporal stability of spatially measured soil water probability density function. Soil Science Society of America Journal, 1985, 49(4): 822-828.

[ 7 ] Bosch D D, Lakshmi V, Jackson T J, Choi M, Jacobs J M. Large scale measurements of soil moisture for validation of remotely sensed data: Georgia soil moisture experiment of 2003. Journal of Hydrology, 2006, 323(1/4) : 120-137.

[ 8 ] Choi M, Jacobs J M. Soil moisture variability of root zone profiles within SMEX02 remote sensing footprints. Advances in Water Resources, 2007, $30(4)$ : 883-896.

[ 9 ] Schneider K, Huisman J A, Breuer L, Zhao Y, Frede H G. Temporal stability of soil moisture in various semi-arid steppe ecosystems and its application in remote sensing. Journal of Hydrology, 2008, 359(1/2): 16-29.

[10] Biswas A, Si B C. Scales and locations of time stability of soil water storage in a hummocky landscape. Journal of Hydrology, 2011, 408( 1/2) : $100-112$.

[11] Gao L, Shao M A. Temporal stability of soil water storage in diverse soil layers. CATENA, 2012, 95: 24-32.

[12] Xu G C, Zhang T G, Li Z B, Li P, Cheng Y T, Cheng S D. Temporal and spatial characteristics of soil water content in diverse soil layers on land terraces of the Loess Plateau, China. CATENA, 2017, 158: 20-29.

[13] Zhao Z M, Shen Y X, Wang Q H, Jiang R H. The temporal stability of soil moisture spatial pattern and its influencing factors in rocky environments. CATENA, 2020, 187: 104418.

[14] Zhao Y, Peth S, Wang X Y, Lin H, Horn R. Controls of surface soil moisture spatial patterns and their temporal stability in a semi-arid steppe. Hydrological Processes, 2010, 24(18) : 2507-2519.

[15] Zhou X, Lin H, Zhu Q. Temporal stability of soil moisture spatial variability at two scales and its implication for optimal field monitoring. Hydrology and Earth System Sciences Discussions, 2007, 4(3): 1185-1214.

[16] Liu B X, Shao M A. Estimation of soil water storage using temporal stability in four land uses over 10 years on the Loess Plateau, China. Journal of Hydrology, 2014, 517 : 974-984.

[17] Li X Z, Shao M A, Jia X X, Wei X R. Profile distribution of soil-water content and its temporal stability along a 1340-m long transect on the Loess Plateau, China. CATENA, 2016, 137: 77-86.

[18] Zhang P P, Shao M A, Zhang X C. Scale-dependence of temporal stability of surface-soil moisture in a desert area in northwestern China. Journal of Hydrology, 2015, 527: 1034-1044.

[19] 陈晓莹, 陈林, 宋乃平, 李敏岗, 吴婷, 杨新国, 王否, 王兴. 荒漠草原两种类型土壤的水分动态对比. 应用生态学报, 2020, 31(5)： 1560- 1570 .

[20] Feng Q, Zhao W E, Qiu Y, Zhao M Y, Zhong L N. Spatial heterogeneity of soil moisture and the scale variability of its influencing factors: a case study in the Loess Plateau of China. Water, 2013, 5(3): 1226- 1242.

[21] 刘宇, 王彦辉, 郭建斌, 刘泽彬, 张桐, 邓秀秀, 徐丽宏, 左海军. 六盘山华北落叶松人工林土壤水分空间异质性的降雨前后变化及其影 响因素. 水土保持学报, 2016, 30(5): 197-204.

[22] 胡勇, 刘良云, 贾建华. 北京山区植被动态及生态恢复的遥感监测. 应用生态学报, 2010, 21(11) : 2876- 2882.

[23] 歌丽巴, 王玉杰, 王云琦, 张会兰, 李云鹏. 北京山区小流域治理现状与建议. 土壤通报, 2015, 46(4): 1011-1017.

[24] 肖雨琳, 魏欣, 刘宝元, 姜洪涛, 郭乾坤, 赵玉明, 王大安. 北京山区果园水平阶整地措施的水土保持效益. 中国水土保持科学, 2013, $11(6): 81-86$.

[25] 潘欣, 王云琦, 高勇, 宋伯岩, 朱楠, 歌丽巴. 石匣小流域整地措施对土壤剪切性质的影响. 水土保持学报, 2016, 30(6): 314-318.

[26] 王贺年, 余新晓, 李轶涛. 北京山区林地土壤水分动态变化. 山地学报, 2011, 29(6): 701-706.

[27］白一茹, 邵明安. 黄土高原雨养区坡面土壤蓄水量时间稳定性. 农业工程学报, 2011, 27(7): 45-50.

[28] Jacobs J M, Mohanty B P, Hsu E C, Miller D. SMEX02: field scale variability, time stability and similarity of soil moisture. Remote Sensing of Environment, 2004, 92(4) : 436-446.

[29] 刘泽涁, 王彦辉, 徐丽宏, 刘宇, 邓秀秀, 王亚莈, 左海军. 六盘山华北落叶松林坡面的土壤水分时间稳定性. 水土保持学报, 2017, 31 (1) : 153-159, 165-165. 
[30] Fu B J, Chen L D. Agricultural landscape spatial pattern analysis in the semi-arid hill area of the Loess Plateau, China. Journal of Arid Environments, 2000, 44(3): 291-303.

[31] Duan L X, Huang M B, Li Z W, Zhang Z D, Zhang L D. Estimation of spatial mean soil water storage using temporal stability at the hillslope scale in black locust (Robinia pseudoacacia) stands. CATENA, 2017, 156: 51-61.

[32] 唐常源, 平田健正, 村岡浩尔. 森林小流域的降雨出流机制的探讨. 地理研究, 1991, 10(3): 87-96.

[33] 高东东, 吴勇, 王糚橦. 山地森林系统小流域降雨过程水循环与地下水补给. 水文地质工程地质, 2014, 41(1): 7-14.

[34] Wang Y, Zhu Q K, Zhao W J, Ma H, Wang R, Ai N. The dynamic trend of soil water content in artificial forests on the Loess Plateau, China. Forests, 2016, 7(10): 236.

[35] 朱绪超, 邵明安, 朱军涛, 张扬建. 高寒草甸生态系统表层土壤水分时间稳定性研究. 农业机械学报, 2017, 48(8): 212-218.

[36] 赵文举, 李晓萍, 范严伟, 郁文, 唐学芬. 压砂地土壤水分的时间稳定性研究. 应用基础与工程科学学报, 2015, 23(6): 1245-1253.

[37] 朱海, 胡顺军, 刘翔, 李浩, 李宜科. 不同龄阶梭梭根区土壤水分时空变化特征. 生态学报, 2017, 37(3): 860-867.

[38] 贾国栋, 余新晓, 邓文平, 等. 北京山区典型树种土壤水分利用特征. 应用基础与工程科学学报, 2013,21(3)：403-411.

[39] 郭梓娟, 宋西德, 赵宏刚. 沙棘-侧柏混交林生物量、林地土壤特性及其根系分布特征的研究. 水土保持通报, 2007, 27(3) : 18-23.

[40] 王勋曜, 孙宏彦, 于辉, 游捷, 王茂良. 天坛公园油松、侧柏大树根系分布特征. 北京农学院学报, 2018, 33(1): 89-98.

[41] 张铁钢, 李占斌, 李鹏, 徐国策, 刘晓君, 靳宇蓉. 土石山区不同植物土壤水分利用方式对降雨的响应特征. 应用生态学报, 2016,27 (5) : 1461-1467.

[42] 徐程扬, 张华, 贾忠奎, 薛康, 杜鹏志, 王京国. 林分密度和立地类型对北京山区侧柏人工林根系的影响. 北京林业大学学报, 2007, 29 (4) : 95-99.

[43] Brocca L, Morbidelli R, Melone F, Moramarco T. Soil moisture spatial variability in experimental areas of central Italy. Journal of Hydrology, $2007,333(2 / 4): 356-373$.

[44] 白一茹, 王幼奇, 王建宇. 黄土丘陵区㫡林土壤水分时间稳定性特征. 应用基础与工程科学学报, 2018,26(1)：23-34.

[45] 潘艳霞, 王新平, 苏廷桂, 李小军, 高艳红. 荒漠人工固沙植被区浅层土壤水分动态的时间稳定性特征. 中国沙漠, 2009, 29(1): 81-86.

[46] Zhao W J, Cui Z, Zhang J Y, Jin J. Temporal stability and variability of soil-water content in a gravel-mulched field in northwestern China. Journal of Hydrology, 2017, 552: 249-257.

[47] 张帅普, 邵明安, 李丹凤. 绿洲-荒漠过渡带土壤蓄水量的空间分布及其时间稳定性. 应用生态学报, 2017, 28(8): 2509-2516.

[48] Mohanty B P, Skaggs T H. Spatio-temporal evolution and time-stable characteristics of soil moisture within remote sensing footprints with varying soil, slope, and vegetation. Advances in Water Resources, 2001, 24(9/10): 1051-1067.

[49] He Z B, Zhao M M, Zhu X, Du J, Chen L F, Lin P F, Li J. Temporal stability of soil water storage in multiple soil layers in high-elevation forests. Journal of Hydrology, 2019, 569: 532-545.

[50］张北赢, 徐学选, 刘文兆. 黄土丘陵沟壑区不同水保措施条件下土壤水分状况. 农业工程学报, 2009, 25(4): 54-58.

[51］穆兴民. 黄土高原土壤水分与水土保持措施相互作用. 农业工程学报, 2000, 16(2): 41-45.

[52] 于洋, 卫伟, 陈利顶, 冯天骄, 杨否, 张涵丹. 黄土丘陵区坡面整地和植被耦合下的土壤水分特征. 生态学报, 2016, 36( 11): 3441-3449.

[53] 白一茹, 王幼奇, 王建宇. 黄土高原雨养区坡面土壤水力学性质空间特征及影响因素. 水土保持研究, 2015, 22(4) : 168-172, 177-177.

[54] 安文明, 韩晓阳, 李宗善, 王帅, 伍星, 吕一河, 刘国华, 傅伯杰. 黄土高原不同植被恢复方式对土壤水分坡面变化的影响. 生态学报, $2018,38(13): 4852-4860$.

[55] Loik M E, Breshears D D, Lauenroth W K, Belnap J. A multi-scale perspective of water pulses in dryland ecosystems: climatology and ecohydrology of the western USA. Oecologia, 2004, 141(2) : 269-281. 